\title{
ANÁLISE ECONÔMICA DO DIREITO TRIBUTÁRIO: LIVRE INICIATIVA, LIVRE CONCORRÊNCIA E NEUTRALIDADE FISCAL
}

\author{
ECONOMICAL ANALYSIS OF TAX LAW: FREE INITIATIVE, \\ FREE COMPETITION, FISCAL NEUTRALITY
}

\author{
Fellipe Cianca Fortes \\ Marlene Kempfer Bassoli
}

\begin{abstract}
Resumo: Concentra-se o estudo na Análise Econômica do Direito dirigida ao Direito Tributário. Quer-se sintonizar a justiça tributária à justiça econômica, no sentido de relação de complementaridade. Este movimento abrange diversas escolas das quais importa a perspectiva normativa que identifica, no próprio Direito, elementos econômicos como fundamento de validade e de eficácia das normas jurídicas. Para tanto é preciso destacar dois princípios relevantes ao Direito (Art. 170 $\mathrm{CF} / 88$ ) e à Economia: Livre Iniciativa e Livre Concorrência, referenciais jurídico-econômicos que devem ser considerados quando o Estado intervém no domínio econômico por meio da tributação, conforme o Art. 146-A da CF/88. Eficácia, livre iniciativa, concorrência serão possíveis a partir do respeito ao Princípio da Neutralidade Fiscal, que possibilita: (i)igualdade de condições no jogo de mercado; (ii) ausência de barreiras estatais de ingresso e permanência no mercado; e (iii) interferência nula ou mínima do Estado no jogo de mercado.
\end{abstract}

Palavras-chave: Análise Econômica do Direito. Tributação. Concorrência. Neutralidade Fiscal.

Abstract: This essay is focused on the economical analysis of tax law. It aims to bring the tax justice close to the economic justice, in a relation of complementation. This movement comprehends many schools which require the normative perspective that identify, inside the Law, economical elements as source of validity and efficacy of the rule of Law. In order to perform that movement, it is necessary two principles important to Law (Article 170, CF/88) and to Economy: Free Initiative and Free Competition, both juridical and economical reference which may be considered when the State intervene into the economical sphere, using taxation according to Article 146-A, from the Constitution of

Artigo produzido a partir da dissertação defendida pelo primeiro autor sob orientação do segundo, para obtenção do título de mestre em Direito Negocial, junto à UEL/PR, em dezembro de 2009.

Mestre em Direito Negocial, professor assistente do IBET e advogado. E-mail: fellipe@ marquesdiniz.com.br.

"Doutora e Mestre em Direito do Estado pela PUC/SP, professora do Mestrado em Direito Negocial da UEL- Londrina/PR e Mestrado em Direito da UNIMAR-Marília/ SP. E-mail: mkempferb@gmail.com.br 
1988. Efficacy, free initiative and free competition are possible when the principle of fiscal neutrality is observed. Which enables: i) equality of conditions inside the markets; ii) lack of State barriers of entering and staying inside a market; and, iii) void or minimal intervention of the State in the market game.

Key-words: Economical Analysis of Law. Taxation. Competition. Fiscal Neutrality.

\section{INTRODUÇÃO}

A Análise Econômica do Direito é um ramo do conhecimento que tem por objeto a relação entre a Ciência Jurídica e a Ciência Econômica, "[...] que busca não só aplicar a teoria econômica ao direito, mas também desenvolver ferramentas epistemológicas não originalmente disponíveis na Ciência Jurídica ou na Ciência da Economia, tradicionalmente reducionistas" (CARVALHO, 2006, p. 81). Esse movimento possui origens nas ciências jurídicas norteamericanas, como alternativa às filosofias utilitaristas e realistas propiciadas pelo sistema do Common Law, porém, o grande destaque que se pode atribuir à Análise Econômica do Direito é seu caráter reacionário no que diz respeito à visão de que o direito é uma realidade e uma disciplina autônomas (CALIENDO, 2009, p. 13). Nesse contexto, pode-se afirmar que a Análise Econômica do Direito Tributário tem por finalidade promover uma aproximação entre direito tributário e economia, aproximação esta essencial para se alcançar a Justiça Fiscal e a justa distribuição de bens.

Conforme leciona Ross (2007), o conceito jurídico de justiça exige que toda e qualquer decisão seja fundamentada em uma norma jurídica e que esta decisão aplique corretamente a norma jurídica. A primeira exigência, segundo Ross (2007, p. 327), "[...] é resultado do direito ser uma ordem social e institucional, diferentemente dos fenômenos morais individuais [...]. Sem um mínimo de racionalidade (previsibilidade, regularidade) seria impossível falar de uma ordem jurídica”. A segunda exigência traz para a pessoa do aplicador do direito a consciência da justiça; determinada decisão é injusta quando tomada sem a observância das formalidades legais ou quanto se verifica o desvio consciente do sentido da lei. A partir destas duas exigências, pode afirmar que a justiça tributária se realiza quando a tributação observe as leis tributárias, construídas por meio do processo representativo democrático, positivem os valores constitucionais. A ordem tributária impõe verdadeiros limites ao poder estatal de tributar os quais, nos termos da $\mathrm{CF} / 88$, se pautam na tributação mediante lei, na segurança jurídica, na previsibilidade mínima das decisões judiciais, na igualdade formal e 
material entre os contribuintes e na observância do mínimo fundamental para a sobrevivência. Estes, também, são referenciais da racionalidade econômica construída ao longo da convivência socioeconômica.

Nesse contexto, pode-se afirmar que recorrer à análise econômica do direito tributário, está-se, buscando sintonizar a justiça tributária à justiça econômica. Não há prevalência de uma em relação à outra, tampouco grau de subordinação, mas sim relação de complementaridade.

Os meios de produção somente poderão alcançar a maximização, bem como a alocação de bens e serviços somente será eficaz, se a tributação não opuser óbices a ponto de influenciar as decisões econômicas, no sentido de desestimular determinadas atividades econômicas em razão dos grandes encargos que as revestem. Por outro lado, a economia traz informações que, abarcadas pela tributação, demonstram em que sentido ou aspecto a distribuição de rendas pode ser incrementada, ou ainda quais características dos tributos que, de uma forma ou de outra, estão colaborando negativamente para as atividades econômicas e de que forma este impacto negativo pode ser sanado. É neste sentido que é possível um profícuo diálogo entre a Economia e o Direito Tributário.

\section{ANÁLISE ECONÔMICA DESCRITIVA DO DIREITO E ANÁLISE ECONOOMICA NORMATIVA DO DIREITO}

Conforma leciona Caliendo (2009, p. 14), a Análise Econômica do Direito não é propriamente uma escola, mas sim um movimento que abrange diversas escolas, algumas delas com verdadeiras distinções entre si, de onde podem ser destacadas duas perspectivas primordiais: a perspectiva descritiva e a perspectiva normativa. A primeira, descritiva, examina o direito tomando por base mecanismos próprios da economia, não jurídicos, ou, nas palavras daquele autor (CALIENDO, 2009, p. 15) "trata da aplicação de conceitos e métodos não jurídicos no sentido de entender a função do Direito e das instituições jurídicas”. Com isso, busca entender o direito e as suas instituições analisando muitas vezes os efeitos econômicos que o ordenamento jurídico produz, como, por exemplo, qual será o impacto de determinada decisão judicial aos agentes econômicos a ela submetidos, se esta decisão, em determinado contexto econômico, era a mais acertada, se os efeitos pretendidos efetivamente serão alcançados ou até mesmo se alcançar os objetivos seria a melhor solução para o caso concreto ou para a sociedade como um todo. É possível observar, neste sentido, que provoca abertura do ordenamento jurídico aos outros ramos do conhecimento, pouco se diferindo, de uma análise filosófica do direito, análise psicológica do direito, análise sociológica do direito, dentre as inúmeras outras possíveis. 
Por se tratar de abertura sistêmica, sua aplicabilidade deve ser vista com ressalvas. No Estado brasileiro onde as competências originalmente são repartidas a partir da Constituição Federal, tamanha abertura somente é possível em hipóteses específicas, a partir de mecanismos de integração do direito, tais como o Princípio da Razoabilidade, nos casos em que o jurista deve ponderar acerca da aplicação de dois ou mais princípios em um dado caso concreto, ou no caso de

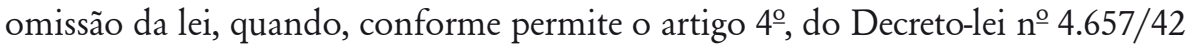
- Lei de Introdução ao Código Civil - o juiz poderá decidir o caso de acordo com a analogia, os costumes e os princípios gerais do direito. Aliás, mesmo nestes casos, não se trata propriamente de abertura do sistema jurídico aos demais ramos do conhecimento, mas sim incidência do próprio direito ao caso concreto, permitindo-se a incorporação de preceitos extrajurídicos.

A perspectiva normativa pretende identificar no próprio direito elementos econômicos, não voltados aos efeitos produzidos em si, mas sim como fundamento de validade e condicionamento de eficácia das normas jurídicas. Nesta última perspectiva, "os fundamentos da eficácia jurídica e mesmo da validade do sistema jurídico deveriam ser analisadas tomando em consideração valores econômicos, tais como a eficiência, entre outros" (CALIENDO, 2009, p. 15), isto é, os conceitos econômicos são utilizados para elaborar os conceitos jurídicos. Tal perspectiva encontra guarida no ordenamento jurídico brasileiro, consoante será tratado no tópico seguinte.

Quando se fala em Análise Econômica Normativa do Direito Tributário, o que se busca é incorporar aos fundamentos e às estruturas tributárias as questõeschave econômicas - eficiência produtiva, eficácia alocativa, justiça distributiva e ordenamento institucional, segundo Rosseti (2003, p. 190) - com o objetivo final de se atingir a justiça tributária, pautada na legalidade, na segurança, na igualdade e na distributividade.

\section{PARÂMETRO CONSTITUCIONAL MEDIATO DA ANÁLISE ECONÔMICA DO DIREITO TRIBUTÁRIO: LIVRE CONCORRÊNCIA (ART. 170, IV CF/88)}

A Constituição consubstancia a base do ordenamento jurídico de um determinado Estado, uma vez que comporta os valores da sociedade e tem por função precípua a formação de unidade jurídico-social-política. Tais pressupostos se remetem à afirmação de Grau (2006, p.166) de que "não se interpreta a Constituição em tiras, aos pedaços”, ela é una e deve ser interpretada sistematicamente. Não se segregam os valores; os mesmos devem ser interpretados em conjunto, conforme leciona Freitas (2004, p. 182): 
Aplicando-se os conceitos formulados à Constituição, esta passa a ser vista como uma rede axiológica de princípios, de regras e de valores de ordem suprema, cuja função precípua é a de, evitando ou superando antinomias axiológicas, dar cumprimento aos objetivos fundamentais do Estado Democrático, entendidos de maneira dominantemente substancial. A sistemática interpretação da Lei Fundamental supõe, assim, uma consideração unitária e aberta que reconheça suas disposições sob o prisma dos nunca inteiramente inócuos princípios superiores. Há, como afirmado, eficácia direta e imediata, no núcleo essencial, de todos os princípios fundamentais.

Tais considerações ganham relevância quando analisadas no contexto do processo legislativo. Os conteúdos sintático, semântico e pragmático dos princípios demonstraram que a Constituição não institui somente regras de estrutura para a criação de novas normas jurídicas, mas também limita a atividade legislativa por meio dos seus valores, sendo defeso ao legislador a edição de leis que destoam do ordenamento constitucional. É justamente por isso que o legislador, ao editar regras tributárias, não pode levar em conta tão somente as limitações ao poder de tributar previstos na Constituição, mas também os fundamentos do Estado - soberania, cidadania, dignidade da pessoa humana e os valores sociais do trabalho e da livre iniciativa, no caso do Estado Brasileiro - os direitos e garantias fundamentais, a ordem social, a ordem econômica e financeira.

O artigo 170, da Constituição Federal de 1988, enuncia como Princípios da Ordem Econômica (a) a soberania nacional, (b) a propriedade privada, (c) a função social da propriedade, (d) a livre concorrência, (e) a defesa do consumidor, (f) a defesa do meio ambiente, $(\mathrm{g})$ a redução das desigualdades regionais e sociais, (h) a busca do pleno emprego, e (i) o tratamento favorecido para as empresas de pequeno porte constituídas sob as leis brasileiras e que tenham sua sede e administração no País, todos fundados na valorização do trabalho humano e na livre iniciativa, com o objetivo principal de assegurar a todos uma existência digna. Estes princípios são essenciais ao dirigismo econômico constitucional, à medida que, conforme aponta Rosseti (2003, p. 314), a economia de mercado possui vários vícios e imperfeições, a exemplo de estruturas de mercado afastadas do protótipo da concorrência perfeita, geração de externalidades negativas, incapacidade para avaliação do mérito de bens e serviços, instabilidade conjectural, ineficiências distributivas, incapacidade para produzir bens públicos e semipúblicos de alto interesse social e ineficácia alocativa, os quais devem ser controlados por meio do direito positivo.

Neste contexto hermenêutico a intervenção do Estado, para regular as condutas no domínio econômico, deve considerar a racionalidade que rege 
este conjunto de relações. Assim, ao intervir por meio de políticas tributárias (normativas, fiscalização, incentivo), atentar para os valores econômicos da liberdade, da oportunidade e o do merecimento que são tutelados, também, pelo direito por meio da livre iniciativa e da livre concorrência. Em razão disso, não basta somente assegurar a liberdade de acesso ao mercado (livre iniciativa), devemse também ser preservada a liberdade de permanência, isto é, a "[...] liberdade de exercer a luta econômica sem a interferência do Estado, bem como sem outros obstáculos impostos pelos demais agentes econômicos privados” (SILVA, 2003, p. 74), o que se faz por meio do Princípio da Livre Concorrência.

O sentido do Princípio da Livre Concorrência parte da ideia de liberdade de competição no mercado a partir da igualdade de condições entre os agentes econômicos. Essa ideia, não obstante, não preenche todo o conteúdo do instituto, uma vez que, segundo Rosseti (2003, p. 485), o ideal da concorrência perfeita, sob a ótica das ciências econômicas, demanda condições "[...] tão rigorosas que, dificilmente, se encontrarão na realidade exemplos que as preencham satisfatoriamente", sendo estas: (a) o número de compradores e de vendedores devem ser grandes o suficiente para que nenhum tenha expressão suficiente para alterar a situação de equilíbrio prevalecente; (b) os produtos transacionados devem ser homogêneos; (c) o mercado deve ser totalmente permeável, sem barreiras de entrada ou de saída; (d) não deve haver quaisquer formas de coalizões entre produtores ou compradores, que agem de forma independente; (e) o preço deve ser estabelecido pelo próprio mercado, sendo resultado de transações transparentes e voluntárias; e (f) tanto os vendedores quanto os compradores devem se submeter aos preços definidos pelo mercado. Nesse mesmo sentido, Ferraz Jr. (1989 apud GRAU, 2006, p. 210) afirma que a livre concorrência pressupõe competitividade, a qual, por sua vez, demanda a "[...] descentralização de coordenação como base da formação dos preços, o que supõe livre iniciativa e apropriação privada dos bens de produção”. O Princípio da Livre Concorrência, nesse contexto, não se limita à liberdade de competição, abrangendo também as condições para que tal liberdade seja assegurada.

\section{PRINCÍPIO DA NEUTRALIDADE FISCAL}

A partir do Princípio da Livre Concorrência, chega-se ao cerne da Análise Econômica do Direito Tributário Normativa: o Princípio da Neutralidade Fiscal. Nas palavras de Ferraz Jr. (Dialética 130, p. 76), a neutralidade fiscal "deriva diretamente da liberdade de iniciativa, seja no sentido da liberdade de acesso ao mercado, seja no de livre conformação e disposição da atividade econômica”, além de que ela "inibe [...] a interferência estatal que impossibilite, juridicamente 
ou de fato, a criação ou a continuidade de empresas dedicadas a atividades lícitas", sendo que tais liberdades e limitações decorrem justamente dos pressupostos da concorrência ideal: a retirada de barreiras estatais garante a suficiência do número de compradores e vendedores, além da entrada a qualquer tempo de novos agentes econômicos, a livre conformação da atividade assegura a homogeneidade dos produtos postos à disposição, e a interferência mínima do Estado, limitada ao estritamente necessário, assegura que não haja coalizões entre produtores ou compradores, que os preços sejam estabelecidos pelo próprio jogo de mercado, aos quais tanto os vendedores e os compradores se submetem.

Nesse contexto, é válido afirmar que a neutralidade fiscal é verificável sob três perspectivas: (i) neutralidade fiscal enquanto igualdade de condições no jogo de mercado; (ii) neutralidade fiscal enquanto ausência de barreiras estatais de ingresso e permanência no mercado; e (iii) neutralidade fiscal enquanto interferência nula ou mínima do Estado no jogo de mercado.

\subsection{Neutralidade Fiscal enquanto Igualdade de Condições no Jogo de Mercado}

A concorrência perfeita, dentre outros elementos, pressupõe o livre jogo de mercado, isto é, os preços dos bens e serviços postos a disposição devem ser ditados pelo próprio mercado, sem interferências externas ou imposições por parte de um dos agentes econômicos concorrentes. Para tanto, deve ser preservado o ambiente concorrencial, no sentido de que todos os participantes do mercado encontrem as mesmas condições para exercerem suas atividades e ofertarem os seus respectivos preços.

Dentre as condutas enunciadas pela Lei no 8.884/94 como infrações à ordem econômica, podem ser destacadas as seguintes como atentatórias à igualdade de condições no mercado: fixar ou praticar, em acordo com concorrente, sob qualquer forma, preços e condições de venda de bens ou de prestação de serviços; obter ou influenciar a adoção de conduta comercial uniforme ou concertada entre concorrentes; dividir os mercados de serviços ou produtos, acabados ou semi-acabados, ou as fontes de abastecimento de matérias-primas ou produtos intermediários; impedir o acesso de concorrente às fontes de insumo, matériasprimas, equipamentos ou tecnologia, bem como aos canais de distribuição; exigir ou conceder exclusividade para divulgação de publicidade nos meios de comunicação de massa; impor, no comércio de bens ou serviços, à distribuidores, varejistas e representantes, preços de revenda, descontos, condições de pagamento, quantidades mínimas ou máximas, margem de lucro ou quaisquer outras condições de comercialização relativos a negócios destes com terceiros; discriminar adquirentes ou fornecedores de bens ou serviços por meio da fixação diferenciada 
de preços, ou de condições operacionais de venda ou prestação de serviços; recusar a venda de bens ou a prestação de serviços, dentro das condições de pagamento normais aos usos e costumes comerciais. Tais condutas, como se pode observar, buscam justamente prevenir eventuais desequilíbrios entre os agentes econômicos, conferindo, direta ou indiretamente, vantagens mercadológicas para alguns em detrimentos dos demais.

Nesse contexto, quando se fala em neutralidade fiscal pela perspectiva da igualdade de condições, tem-se que a tributação deve ser instituída e regulamentada de tal forma que não cause desigualdades entre aqueles que se encontram sob a mesma situação jurídica, isto é, salvo casos necessários e justificados, o tributo não pode causar desequilíbrios entre agentes econômicos competidores diretos. De acordo com Ferraz Jr. (2005, p. 733), a neutralidade fiscal, sob a perspectiva da igualdade, será ferida quando "ficar demonstrado que, por lei, as relações competitivas entre empresas concorrentes em igualdade de condições venham a ser restringidas por uma medida (legal) que efetivamente crie para elas uma diferença que passe a existir apenas em virtude da própria medida”, sendo que a tal interferência pode ser tanto manifesta, quanto indireta, isto é, "se uma atividade econômica foi atingida por uma medida legal aparentemente geral, mas que, de fato, dificulta para uns em benefício de outros” (FERRAZ JR., 2005, p. 734).

É preciso destacar que, quando se fala em igualdade de condições, está-se referindo a uma igualdade formal, isto é, o direito positivo, por meio dos seus mecanismos, visa anular, ou ao menos diminuir, as desigualdades empíricas existentes entre os agentes econômicos. Desta forma, inexiste qualquer violação à neutralidade fiscal sob a perspectiva ora abordada no caso de a legislação tributária atribuir tratamento diverso a contribuintes que se encontrem em situações jurídicas e econômicas diversas, desde que tais diferenças, bem como as respectivas medidas niveladoras, sejam devidamente previstas e justificadas. Como exemplos, podem ser citados os artigos 146, III, d, e 170, IX, da Constituição Federal, que prevêem tratamento diferenciando, inclusive na seara tributária, para micro e pequenas empresas: empresas de porte, já adaptadas ao mercado onde atuam e detentoras de know-how e tecnologia, acumulam grande parcela do poder econômico e conseguem, com mais facilidade, se impor perante os consumidores, tendendo, assim, a dominar a concorrência, de modo que a Constituição Federal prevê uma série de medidas que visam diminuir as diferenças entre tais empresas e aquelas de menor porte, e, por consequência, permitir a estas últimas o acesso e a permanência no mercado, podendo competir com as demais de forma mais balanceada.

Portanto, salvo para nivelar desigualdades inerentes aos próprios agentes econômicos, à tributação é vedado causar desequilíbrios na livre concorrência. 


\subsection{Neutralidade Fiscal enquanto Ausência de Barreiras Estatais de Ingresso e Permanência no Mercado}

Pela segunda perspectiva da neutralidade fiscal, a tributação não pode impor barreiras para as empresas ingressarem ou permanecerem no mercado. A proibição de barreiras é conduta também amparada pela Lei $\mathrm{n}^{\circ}$ 8.884/94, que em seu artigo 21 tipifica com infração à ordem econômica nacional liminar ou impedir o acesso de novas empresas ao mercado e criar dificuldades à constituição, ao funcionamento ou ao desenvolvimento de empresa concorrente ou de fornecedor, adquirente ou financiador de bens ou serviços.

$\mathrm{Na}$ senda do que foi exposto no tópico anterior, é preciso salientar que nem toda barreira tributária infringe a neutralidade fiscal. Há mecanismos tributários que, em razão de outros princípios constitucionais, são necessários à fiscalização e à arrecadação e acabam impondo óbices de constituição ou de exercício regular de empresas; todavia, estes mecanismos, para serem concorrencialmente válidos, devem atingir, de forma indiscriminada, toda e qualquer empresa que exerça a atividade econômica a que se referem, sem que nenhuma delas seja diretamente beneficiada, ou diretamente prejudicada, por tais medidas em dissonância às demais.

\subsection{Neutralidade Fiscal enquanto Interferência Nula ou Mínima no Jogo de Mercado}

Pela última perspectiva da neutralidade fiscal, o preço do bem ou do serviço deve ser ajusta de acordo com o jogo de mercado, sem qualquer interferência dos concorrentes ou de terceiros, seja direta, seja indiretamente. A manipulação ou a interferência indevida de preços também é rechaçada pela Lei no $8.884 / 94$, que traz como condutas violadoras da ordem econômica nacional utilizar meios enganosos para provocar a oscilação de preços de terceiros, vender injustificadamente mercadoria abaixo do preço de custo e impor preços excessivos, ou aumentar sem justa causa o preço do bem ou do serviço.

Nesse contexto, sob a perspectiva da interferência estatal nula ou mínima no jogo de mercado, a neutralidade fiscal exige que a tributação deve ser economicamente nula, ou mínima o possível, isto é, o preço final do produto posto à disposição no mercado não deve sofrer influência nenhuma da respectiva tributação, ou, se isto não for possível, sofrer influência mínima, repassando ao consumidor final toda a carga tributária que onera a cadeia de produção. Conforme leciona Basto (1991 apud TEIXEIRA, 2002, p. 68) o tributo

[...] é neutro nos seus efeitos sobre a produção se não leva os produtores a modificar os seus métodos de produção, isto é, a forma como organizam os seus negócios, e 
diz-se neutro nos seus efeitos sobre o consumo se não conduz os consumidores a modificar as suas escolhas entre os diferentes bens que procuram.

Em uma economia capitalista, os preços dos produtos devem ser definidos pelo próprio jogo do mercado, cabendo ao Estado tão somente ações positivas no sentido de coibir as externalidades causadas pelo próprio regime de produção, fiscalizando, incentivando ou planejando as atividades econômicas quando assim se fizer necessário. De certo que a tributação é necessária à manutenção e sobrevivência do Estado, tendo como uma das suas principais bases a produção e a circulação de bens e serviços, não havendo como se desvencilhar por completo o preço dos produtos dos respectivos tributos incidentes durante a cadeia de produção; porém, o que se deve buscar é a coibição dos excessos da tributação, vale dizer, o tributo, e seus mecanismos inerentes, não podem impactar o preço final do produto mais que o necessário para as suas finalidades.

A legislação tributária, especificamente, já traz em seu bojo algumas disposições que, claramente, visam anular os efeitos da tributação no preço final do produto. O mais notório destes mecanismos é o Princípio da Não Cumulatividade, inerente ao Imposto Sobre Produtos Industrializados e ao Imposto Sobre a Circulação de Mercadorias e Serviços, a partir do qual todo o tributo incidente sobre determinada etapa de industrialização e/ou de circulação é repassada para a etapa seguinte, onde será compensado com o tributo devido na operação subsequente e, assim, de forma sucessiva, até se atingir o consumidor final. Por este instituto, busca-se, simultaneamente, impedir a tributação em cascata, isto é, a incidência cumulativa dos tributos sobre as várias etapas da cadeia de produção, principalmente sobre as bases tributadas anteriormente, e a desoneração dos produtores, dirigindo a carga tributária ao consumidor final. Ainda como exemplos, podem ser citados também a possibilidade, na seara federal, de se compensar créditos acumulados com outros tributos, o ressarcimento de tributos cujo produto final é destinado à exportação, bem como, na seara estadual, a paulatina permissão de os contribuintes se apropriarem de créditos decorrentes da aquisição de bens de consumo e destinados ao ativo fixo. Há hipóteses, entretanto, que o próprio tributo em si, ou os institutos a ele inerentes, causam distorções no preço final do produto, distorções estas evitáveis e que ultrapassam a barreira do mínimo necessário, devendo, assim, serem coibidas em razão da neutralidade fiscal.

Pelo exposto, o Princípio da Livre Concorrência busca formar um mercado com base na igualdade de condições, com os fatores de produção e os preços dos bens e serviços se regulando de acordo com as forças de mercado, independente de qualquer influência externa, principalmente estatal, cuja interferência fica 
relegada tão somente para fiscalizar, incentivar ou planejar quando assim se fizer necessário. E, quando se fala em afastamento do Estado na conformação final dos preços dos bens e serviços disponibilizados, deve-se afastar qualquer impacto que a tributação possa causar na racionalidade do mercado, ou buscar reduzi-lo ao máximo, buscando, com isso, a neutralidade fiscal.

\section{PARÂMETRO CONSTITUCIONAL IMEDIATO DA ANÁLISE ECONÔMICA DO DIREITO TRIBUTÁRIO: ARTIGO 146-A}

Na senda do que foi exposto no tópico anterior, o artigo 170, IV, da Constituição Federal, consubstancia o fundamento mediato da Análise Econômica Normativa do Direito Tributário, uma vez que, a partir de uma interpretação sistemática, impõe ao Estado verdadeiras limitações ao poder de tributar, no sentido de que a tributação deve ser concorrencialmente neutra, isto é, não causar interferência, ou causar interferência mínima, no jogo de mercado. Porém, não obstante a Constituição Federal já contemplar em sua redação originária a necessária comunicação entre o direito tributário e determinados preceitos econômicos, a Emenda Constitucional no 42/2003 inseriu ao texto constitucional o artigo 146A, o qual determina expressamente que "a Lei Complementar poderá estabelecer critérios especiais de tributação, com o objetivo de prevenir desequilíbrios da concorrência, sem prejuízo da competência de a União, por lei, estabelecer normas de igual objetivo" (BRASIL, 1988). Desta maneira, a Análise Econômica Normativa do Direito Tributário, mais do que uma simples área do conhecimento, foi positivada pelo direito explicitando diretamente o artigo 146-A a comunicação entre a economia e o direito tributário.

O impacto negativo dos tributos na economia se dá por diversas formas, as quais podem ser agrupadas entre hipóteses normativas e fáticas. As hipóteses normativas dizem respeito às próprias características do tributo, isto é, como o tributo, da forma como criado e instituído pelo ordenamento jurídico, influencia a economia e, via de consequência, as decisões econômicas. Enquadram-se aqui questões polêmicas como a compensação de débitos próprios com créditos de terceiros adquiridos com grandes deságios, planejamento tributário e elisão/ evasão fiscal, guerra fiscal e a não abrangência de determinadas atividades pelas bases imponíveis. Tais hipóteses se referem ao campo da Análise Econômica Normativa do Direito Tributário. Por sua vez, as hipóteses fáticas vão além do campo sintático do tributo, abrangendo questões como o inadimplemento e a sonegação, mais afeitos à Análise Econômica Descritiva do Direito Tributário. De acordo com Derzi (2004, p. 346) o artigo 146-A estabelece como diretriz que "[...] não devem ser tolerados os desequilíbrios da concorrência provocados pelos 
tributos”, de modo que a sua função é justamente inibir tais impactos, permitindo que a concorrência flua livremente.

À primeira vista, o artigo 146-A enuncia uma regra de competência, outorgando à União o poder de instituir, por meio de lei complementar de caráter nacional (vinculante para todos os Entes Federativos), normas que visam prevenir ou anular as distorções concorrenciais provocadas pelos tributos. Com isso, a União, além da competência outorgada pelo artigo 174 para fiscalizar, incentivar e planejar as atividades econômicas cabe, também, intervir diretamente na tributação tanto dos Estados, quanto dos Municípios, quando esta ferir os preceitos concorrenciais. Mais do que somente enunciar tal regra, é válido afirmar que o artigo 146-A da CF/88 positiva, expressamente, no ordenamento jurídico o Princípio da Neutralidade Fiscal, conforme visto nos tópicos anteriores era construído implicitamente a partir dos Princípios da Ordem Econômica.

Portanto, as limitações ao poder de tributar decorrentes das diversas perspectivas da neutralidade fiscal que anteriormente decorriam de uma interpretação sistemática da Constituição Federal, desde a edição da Emenda Constitucional n⿳ 42/2003, passaram a compor o Sistema Tributário Nacional, não restando dúvidas de que a instituição e a construção da regra-matriz de incidência tributária dos tributos estão vinculadas aos preceitos econômicos. Desta forma, conforme defendido pela Análise Econômica Normativa do Direito, o Direito Tributário tem suas competências e regras plenamente vinculadas aos preceitos econômicos, sendo destes indissociáveis.

Assim, demonstrada a pertinência do diálogo entre o Direito Tributário e a racionalidade econômica, segue-se para a análise de três situações práticas que revelam o acerto e desacerto da atual legislação e mecanismos da tributação diante da neutralidade fiscal e da livre concorrência.

\section{PERSPECTIVAS DA NEUTRALIDADE FISCAL DIANTE DA SUBSTITUIÇÃO TRIBUTÁRIA E PAUTA FISCAL}

Em decorrência da grande sonegação no setor de bebidas, aliado à dificuldade de fiscalização, a Secretaria da Receita Federal determinou que fossem instalados medidores de vazão nas fábricas de cerveja e, posteriormente, também nas fábricas de refrigerante. A função é simples: como a tributação neste ramo incide sobre o volume comercializado, o controlador, aliado à sistemática de substituição tributária (pauta fiscal), permitiria à Administração Pública recolher todo o tributo incidente na cadeia produtiva logo na fonte distribuidora, não mais precisando alcançar as dificuldades do varejo. Tal sistemática, contudo, trouxe a seguinte consequência: a pauta fiscal para a substituição tributária é construída a 
partir de preços médios no mercado, o que faz com que os produtos de melhor qualidade, e, em decorrência, mais caros, sejam tributados a menor, enquanto os produtos mais baratos, em geral de pequenos produtores, sofrem uma elevação na tributação e, como não poderia deixar de ser, no seu preço final, repercutindo diretamente na livre concorrência.

Nas discussões travadas perante os Tribunais as grandes produtoras de bebidas defenderam que as pequenas produtoras teriam vantagens comerciais sem o controle de vazão - podendo se beneficiar, inclusive, da inadimplência - enquanto, em sentido contrário, as pequenas produtoras defendiam que sua submissão ao regime tributário das grandes não permite a sua sobrevivência, visto que a pauta fiscal majorava seus preços e os aproximava das bebidas já consagradas no mercado, impedindo, assim, a concorrência igualitária.

A solução dada pelo Tribunal Regional Federal da $1^{\underline{a}}$ Região ao deferir a medida liminar no agravo de instrumento no 2007.01.00.016002-5, de relatoria da Desembargadora Federal Maria do Carmo Cardoso, interposto pela Associação dos Fabricantes de Refrigerantes do Brasil - AFREBRAS em face da União (Fazenda Nacional) - foi a seguinte:

O intuito maior da instalação dos medidores de vazão está no controle da sonegação fiscal, que, inicialmente, ocorreu em relação às fabricantes de cervejas, e, agora, terá aplicação às fabricantes de refrigerantes e água. No entanto, não se pode negar que, ao tempo em que se institui modelo de controle, cujo ônus de instalação pode acarretar prejuízos de grande monta para as fabricantes de médio e pequeno porte, a manutenção e o fortalecimento das empresas de grande porte é evidente. Enquanto isso, inegável que a sonegação fiscal tem suporte em todas as categorias de empresas, sejam as de pequeno e médio, como as de grande porte. Ressalto a necessidade, a importância e dever de fiscalização desses serviços, especialmente para o fim de evitar a evasão fiscal, contudo, questiono as consequências desse modelo de controle, relativamente à formação de monopólio e concorrência desleal. Tais constatações iniciais me levam a enfrentar a questão sob o aspecto da possível violação aos princípios da igualdade, proporcionalidade, razoabilidade, da isonomia e da livre iniciativa.

Sob este fundamento, as pequenas e médias indústrias de bebidas foram dispensadas da instalação do controlador de vazão, visando, com isso, à proteção da concorrência e da livre iniciativa, sendo tal decisão, ao que parece, acertada: ao se ponderar acerca da neutralidade fiscal enquanto igualdade de condições, efetivamente se verifica que a forma mais eficaz de seus produtos menores, mais novos ou de menor qualidade concorrerem com os demais e se sustentar no mercado é por meio de preços reduzidos, uma vez que, certamente, podendo o 
consumidor escolher entre dois produtos com mesmo preço, aquele de qualidade superior prevalecerá. Porém, a pauta fiscal, da forma como elaborada - média de preços -, acaba por majorar demasiadamente os preços das bebidas das pequenas indústrias, acabando com a sua possibilidade de concorrência.

\section{PERSPECTIVAS DA NEUTRALIDADE FISCAL DIANTE DAS BARREIRAS TRIBUTÁRIAS PARA EMPRESAS TABAGISTAS}

Pela segunda perspectiva, foi afirmado que os mecanismos tributários não podem impor óbices que dificultem ou impossibilitem o ingresso e a permanência do agente econômico no mercado, salvo se estes forem essenciais à fiscalização e à arrecadação e atingirem indiscriminadamente todas as empresas que exercerem a atividade econômica a que se referem.

O Supremo Tribunal Federal, quando do julgamento da Medida Cautelar em Ação Cautelar no 1657/RJ, de relatoria do Ministro Joaquim Barbosa, teve a oportunidade de analisar o direito tributário a partir desta perspectiva da neutralidade fiscal, suscitando, inclusive, a aplicação do artigo 146-A. No caso, empresa tabagista, diante de procedimento fiscal encabeçado pela Secretaria da Receita Federal do Brasil voltado à verificação das condições para a manutenção do registro especial previsto no Decreto-lei $\mathrm{n}^{-}$1.593/77, essencial para este ramo de atividades e cujo um dos seus requisitos é a adimplência fiscal, ajuizou medida cautelar para assegurar seu direito ao livre exercício de atividade econômica lícita, aduzindo que ao Estado é vedado adotar medidas que impliquem o embaraço ou a vedação do exercício profissional como forma de coagir o sujeito passivo a cumprir as obrigações tributárias. Proposta a medida cautelar visando atribuir efeito suspensivo ao recurso extraordinário interposto pela empresa, o Ministro Cezar Peluso expõe:

Ao investigar a ratio iuris da necessidade de registro especial para a atividade de produção de cigarros, vê-se, logo, que provém de norma inspirada não só por objetivos arrecadatórios, senão também por outras finalidades que fundamentam a exigência jurídica dos requisitos previstos para a manutenção do registro especial, entre os quais se inclui o da regularidade fiscal. Esta finalidade extrafiscal que, diversa da indução do pagamento de tributo, legitima os procedimentos do Decretolei no $1.593 / 77$, é a defesa da livre concorrência. Toda a atividade da indústria de tabaco é cercada de cuidados especiais em razão das características desse mercado, e, por isso, empresas em débito com tributos administrados pela SRF podem ver cancelado o registro especial - que é verdadeira autorização para produzir bem como interditados os estabelecimentos. Não há impedimento a que a norma tributária, posta regularmente, hospede funções voltadas para o campo da defesa da liberdade de competição no mercado, sobretudo após a previsão textual do art. 146-A da Constituição da República. 
No caso, consoante se infere da decisão, o Supremo Tribunal Federal considerou válida a barreira imposta pela tributação, visto que esta, ao contrário do defendido pela empresa tabagista, não impede o livre exercício da atividade econômica, mas, em sentido oposto, preserva a sua saudável execução, à medida que impede a inadimplência fiscal no setor e coíbe o uso deste artifício como forma de conseguir uma vantagem concorrencial.

\section{PERSPECTIVAS DA NEUTRALIDADE FISCAL DIANTE DA BASE DE CÁLCULO POR DENTRO DO IMPOSTO SOBRE A CIRCULAÇÃO DE MERCADORIAS}

A Constituição Federal, em seu artigo 155, § 2º, XII, i, determina que cabe à lei complementar fixar a base de cálculo do imposto sobre a circulação de mercadorias, '[...] de modo que o montante do imposto a integre, também na importação do exterior de bem, mercadoria ou serviço’.

Tanto o imposto sobre serviços de qualquer natureza, quanto o imposto sobre produtos industrializados, são impostos cujo cálculo se dá de forma direta, vale dizer, por fora, aplicando-se a alíquota sobre a base de cálculo correspondente, obtendo - e se identificando facilmente -, com isso, o tributo devido. Toma-se o seguinte exemplo hipotético, onde ' $\mathrm{V}_{\mathrm{op}}$ ' é o valor da operação e a alíquota aplicável é de $18 \%$ :

$$
\begin{gathered}
\text { IPI }=\mathbf{V}_{\text {op }} \times \text { Alíquota } \\
\text { IPI }=\mathrm{R} \$ 1.000,00 \times 18 \% \\
\text { IPI }=\mathrm{R} \$ 180,00
\end{gathered}
$$

Neste exemplo, o valor final do produto corresponderá a $\mathrm{R} \$ 1.180,00$, isto é, o valor do produto acrescido da carga tributária a ele inerente. No imposto sobre a circulação de mercadorias, porém, o cálculo se dá de forma diversa, devendo o imposto ser incorporado à sua própria base de cálculo, a partir da seguinte fórmula matemática: B.C.ICM $=\mathrm{V}_{\mathrm{M}} /$ (1 - Alíquota), onde "B.C.ICM" é a base de cálculo do imposto e " $\mathrm{V}_{\mathrm{M}}$ " é o valor das mercadorias. Tomando-se novamente o exemplo hipotético teria:

$$
\begin{gathered}
\text { B.C.ICM }=\mathrm{V}_{\mathrm{M}} /(1-\text { Alíquota }) \\
\text { B.C.ICM }=\mathrm{R} \$ 1.000,00 /(1-18 \%) \\
\text { B.C.ICM }=\mathrm{R} \$ 1.000,00 / 0,82 \\
\text { B.C.ICM }=\mathrm{R} \$ 1.219,51
\end{gathered}
$$

Aplicando-se a alíquota de $18 \%$ sobre tal base, teria:

$$
\begin{gathered}
\mathrm{ICM}=\text { B.C.ICM x Alíquota } \\
\mathrm{ICM}=\mathrm{R} \$ 1.219,51 \times 18 \% \\
\mathrm{ICM}=\mathrm{R} \$ 219,51
\end{gathered}
$$


Nota-se que, em razão de se ter embutido o imposto sobre a circulação de mercadorias em sua base de cálculo, o tributo, ao final, sofreu um acréscimo de $\mathrm{R} \$ 39,51$ em relação ao cálculo por fora, totalizando $\mathrm{R} \$ 219,51$. A mercadoria, que seria comercializada a $\mathrm{R} \$ 1.180,00$ se a tributação fosse direta, é comercializada a R $\$ 1.219,51$, sendo $21,51 \%$ a alíquota efetiva. Sob tal sistemática, a alíquota efetiva do imposto sempre será maior do que a sua alíquota nominal, resultando, em consequência, que o imposto destacado em nota fiscal e recolhido aos cofres públicos também será maior.

No bojo de uma cadeia produtiva, agregando ao produto $\mathrm{R} \$ 1.000,00 \mathrm{em}$ cada operação, o efeito do cálculo por dentro do imposto sobre a circulação de mercadorias se dá conforme apresentado na Figura 1.

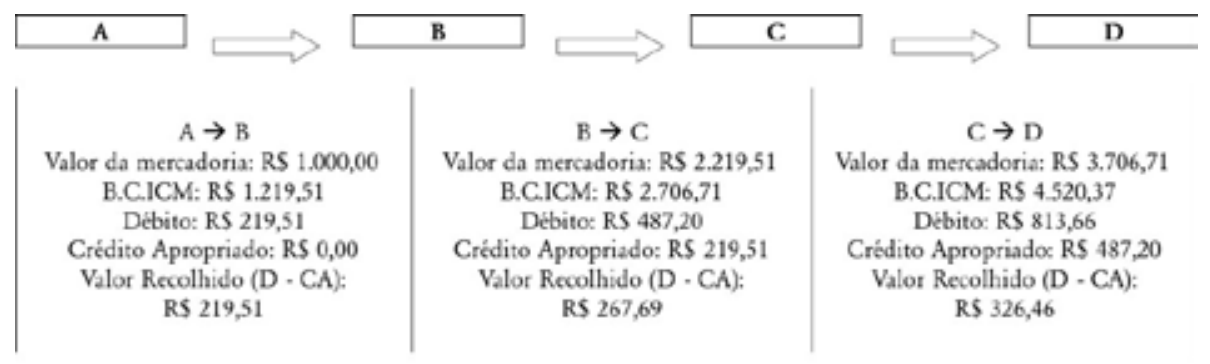

Figura 1. Efeito do cálculo por dentro do imposto sobre a circulação de mercadorias na cadeia de produção.

O cálculo por dentro do imposto sobre a circulação de mercadorias traz uma cumulatividade residual: o ônus da carga tributária do imposto está embutido no valor da mercadoria, sobre a qual, na etapa seguinte, incidirá, uma vez mais, o imposto, o que não é compensado pelo crédito apropriado. O resultado é a incidência de imposto sobre imposto, acarretando, no exemplo acima, um acréscimo de $\mathrm{R} \$ 706,71$ no valor final da mercadoria, sendo que, destes, $\mathrm{R} \$ 166,71$ correspondem à cumulatividade residual.

Note-se que caso o imposto fosse apurado por fora, o resultado seria de acordo com o apresentado na Figura 2. 


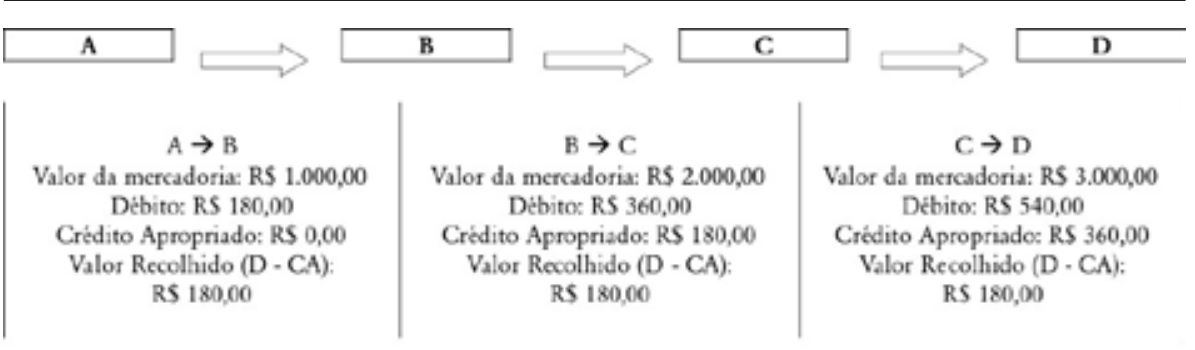

Figura 2. Cálculo por fora do imposto sobre a circulação de mercadorias.

Nesta hipótese, o imposto acrescentaria apenas $\mathrm{R} \$ 540,00$ no valor final da mercadoria, além de que a alíquota incidente efetivamente seria $18 \%$, evidenciando que o cálculo por dentro do imposto sobre a circulação de mercadorias exerce influência direta na formação do preço das mercadorias disponibilizadas no mercado: o imposto, ao invés de consubstanciar mero acréscimo no valor final representando o montante da carga tributária incidente na cadeia de circulação, podendo ser facilmente destacado, é incorporado ao preço da mercadoria em cada uma das operações, causando desvios no respectivo valor e atingindo o consumidor final de forma majorada, distorcendo o jogo de mercado por ter que se adaptar e assentar a concorrência não somente de acordo com a demanda e a disponibilidade de arcar com o custo do bem, mas também com toda a carga tributária cumulada que compõe o seu teor, prejudicando a livre concorrência. O Supremo Tribunal Federal, no julgamento do Recurso Extraordinário nº 212.209 (julgado em 23/06/1999), decidiu pela constitucionalidade do cálculo por dentro do imposto sobre a circulação de mercadorias.

\section{CONCLUSÕES}

Ganha relevância o ramo do conhecimento denominado Análise Econômica do Direito, o qual busca a análise do fenômeno jurídico por meio de instrumentos econômicos. Tal método, aplicado ao direito tributário traz importantes informações acerca do impacto fiscal nos meios de produção, no preço final dos produtos postos à disposição e, via de consequência, no jogo de mercado.

Ao se proceder a uma análise econômica do direito tributário, o que se busca, em última instância, é concretizar os ideais de justiça econômica e de justiça tributária. A primeira é alcançada à medida que se alocam de forma eficiente os bens da sociedade. A segunda à medida que a legislação é cumprida, principalmente, no que diz respeito aos princípios tributários da legalidade e da capacidade contributiva.

A Constituição Federal Brasileira de 1988 possui dois parâmetros que permitem o estudo do direito por meio da Análise Econômica do Direito Tributário, sendo 
o artigo 170, IV, a parâmetro mediato, e o artigo 146-A, o parâmetro imediato. O artigo 170, IV, da Constituição Federal, consubstancia o fundamento mediato da Análise Econômica Normativa do Direito Tributário em razão de impor ao Estado verdadeiras limitações ao poder de tributar, no sentido de que a tributação deve ser concorrencialmente neutra. Já o artigo 146-A, determina expressamente que "a Lei Complementar poderá estabelecer critérios especiais de tributação, com o objetivo de prevenir desequilíbrios da concorrência, sem prejuízo da competência de a União, por lei, estabelecer normas de igual objetivo”. Assim, a Análise Econômica Normativa do Direito Tributário positivada pelo direito brasileiro, deixando clara a comunicação entre a economia e o direito tributário.

A partir da definição do conteúdo semântico do Princípio da Livre Concorrência, chega-se ao cerne da Análise Econômica do Direito Tributário Normativa: o Princípio da Neutralidade Fiscal. Este tem três perspectivas: (i) neutralidade fiscal enquanto igualdade de condições no jogo de mercado; (ii) neutralidade fiscal enquanto ausência de barreiras estatais de ingresso e permanência no mercado; e (iii) neutralidade fiscal enquanto interferência nula ou mínima do Estado no jogo de mercado.

Assim, pode-se afirmar que a Neutralidade Fiscal é uma verdadeira limitação ao poder de tributar consistente na inibição da interferência estatal, por meio dos tributos e dos seus mecanismos, que impossibilite, juridicamente ou de fato, a criação ou a continuidade de empresas dedicadas a atividades lícitas. $\mathrm{O}$ respeito a este princípio viabiliza a livre concorrência, que por sua vez preserva de modo de saudável o mercado interno declarado, em nível constitucional (Art. 219 CF/88), como patrimônio nacional.

\section{REFERÊNCIAS}

CALIENDO, Paulo. Direito tributário e análise econômica do direito: uma visão crítica. Rio de Janeiro: Elsevier, 2009.

CARVALHO, Cristiano. Deveres instrumentais e custos de transação. In: CONGRESSO NACIONAL DE ESTUDOS TRIBUTÁRIOS, 4., 2006, São Paulo. Tributação e processo. São Paulo: Noeses, 2006.

DERZI, Misabel Abreu Machado. Não-cumulatividade, neutralidade, pis e cofins e a emenda constitucional no 42/03. In: ROCHA, Valdir de Oliveira (Org.). Grandes questões atuais do direito tributário. São Paulo: Dialética, 2004. v. 8.

FERRAZ JR., Tércio Sampaio. Obrigação tributária acessória e limites da imposição: razoabilidade e neutralidade concorrencial do estado. In: FERRAZ, Roberto (Coord.). Princípios e limites da tributação. São Paulo: Quartier Latin, 2005. 
FREITAS, Juarez. A interpretação sistemática do direito. 4. ed. rev. e ampl. São Paulo: Malheiros, 2004.

GRAU, Eros Roberto. A ordem econômica na constituição de 1988. 11. ed. rev. e atual. São Paulo: Malheiros, 2006.

ROSS, Alf. Direito e justiça. 2. ed. Bauru: Edipro, 2007.

ROSSETI, José Paschoal. Introdução à economia. 20. ed. São Paulo: Atlas, 2003.

SILVA, Américo Luís Martins da. A ordem constitucional econômica. 2. ed. Rio de Janeiro: Forense, 2003.

TEIXEIRA, Alessandra Machado Brandão. A tributação sobre o consumo de bens e serviços. Belo Horizonte: Mandamentos, 2002.

Artigo recebido em 07/10/10 e aprovado para publicação em 18/10/10 
